\title{
Living the paleofantasy?
}

\author{
Briana Pobiner
}

Keywords: Evolution; Paleodiet; Human evolution; Evolution misconceptions

Paleofantasy: What Evolution Really Tells Us about Sex, Diet, and How We Live, by Marlene Zuk. ISBN 978-0393-08137-4 New York: W. W. Norton \& Company, 2013. 328pp. H/b \$27.95.

My particular interest in this topic is my research focus on the evolution of human diets, and the "paleodiet" fad has made my research relevant recently. I'm always on the lookout for articles and books that communicate about prehistoric diets - and human evolution in general - to the general public. This book does a superb job. In fact, I've been asked by several people if and when I might want to write a book, and now I've been telling them that the book I'd want to write has already been written; this one!

Dr. Marlene Zuk is a Professor in the College of Biological Sciences at the University of Minnesota, studying how natural and sexual selection pressures shape the behavior, life history, and morphology of animals. Specifically, her lab investigates the conflict between natural and sexual selection in Pacific field crickets. While her core research may sound a bit dry, this book is absolutely drenched with witty, lively, accessible information about examples of past and present evolution as they pertain to the modern myth that we have not had time to evolve in response to modern pressures and circumstances. How can you not immediately be hooked by a book whose first sentence is "The first thing you have to do to study 4,000year-old DNA is take off your clothes"?

In the introduction, and repeatedly throughout the book, Zuk elegantly breaks down this "paleofantasy" and dispels many myths on which it rests. Some of the main ones include the idea that at some idyllic point in the past, we were "perfectly adapted to our environments" (p. 7), when in fact organisms with seemingly flawless adaptations are actually "full of compromises, jury-rigged like all other organisms" (p. 8) that "we have trade-offs and "good

Correspondence: pobinerb@si.edu

Department of Anthropology, Smithsonian Institution, 10th Street and Constitution Avenue NW, Washington DC, 20560, USA enough" solutions that linger from our evolutionary history" (p. 8), and that evolution involved costs and benefits. One of my favorite analogies of hers is that "our adaptation is more like a broken zipper, with some teeth that align and others that gape apart" (p. 8).

Chapter 1, "Cavemen in Condos", gives a nice outline of major milestones in human evolution, presents examples of what she states are the three main sources of information about early humans: fossils and artifacts, modern hunter-gatherers, and modern apes (especially chimpanzees), but then rightfully warns against extrapolating too much from any of these sources wholesale to the prehistoric record.

In Chapter 2, "Are We Stuck?", Zuk argues against the idea that agriculture is the worst thing that ever happened to us, invoking Spencer Wells' notion that every major disease affecting modern human populations "has its roots in the mismatch between our biology and the world we have created since the advent of agriculture" (p. 46). Yes, aspects of agriculture increased human diseases and malnutrition, but she points out that people recovered quickly from the decrease in body size. Here, Zuk explains that an increase in population is detrimental as far as overcrowding and more demands on resources like clean water, but in yet another witty analogy she notes that more people means more genes for evolution to act on: "Think of mutations as lottery tickets: the vast majority of them are losers, but the only way to increase your chances of winning is to buy a large number of entries" (p. 55). This chapter ends with an introduction to the idea of the Environment of Evolutionary Adaptedness (EEA), the root of the idea that we have not had enough time to adapt to our modern environments as far as our psychology and behavior - hence people trying to write off their predilection for junk food or proclivity for extramarital affairs because these things were beneficial in the ancestral environment. She then ends with a discussion of why identifying the particular genes that have undergone 
selection is important to understanding our evolution and the recent focus on developmental and regulatory genes.

Chapter 3, "Crickets, Sparrows, and Darwins - or Evolution before Our Eyes", begins with an engaging story of Zuk's own research on crickets in Australia and nearby Pacific islands and trying to understand why a seemingly deleterious behavior - the lack of structures in male crickets enabling to call to attract females - makes sense when taking into account parasitic flies who are also attracted to the cricket's calls. Zuk then succinctly outlines many examples of rapid evolution in a timescale we can actually observe, with adaptations occurring in only a few generations, in organisms as diverse as her crickets, fish, humans, birds, snails, lizards, and plants. These examples are peppered throughout the book, but mainly concentrated in the Introduction and Chapter 3. As an evolutionary anthropologist, when I am giving public lectures, I consistently get questions about whether we or other organisms are still evolving; Zuk has given me an arsenal of excellent examples to use.

Chapter 4, "The Perfect Paleofantasy Diet: Milk", explores one of the best examples of recent evolution in humans the ability to digest lactose. Zuk thoroughly details the steps in this process - the domestication of cattle, why the ability to digest dairy after weaning would be beneficial, and the studies of recent populations with lactase persistence. She notes how this is a great example of how our genes and cultural activities interact. She also introduces the concept of genetic drift and "hitchhiker" genes, and notes that even a small (3\%) increase in reproductive fitness of individuals with lactase persistence would result in this gene being widespread after only about 7,000 years. Coincidentally the time estimate for the most recent evidence pinpointing these mutations? Hardly.

Chapter 5, "The Perfect Paleofantasty Diet: Meat, Grains, and Cooking", introduces the idea of the paleodiet as most people know it: a focus on meat and avoidance of grains based on the assumption that highly processed, refined foods high in starches are responsible for all "diseases of civilization" (p. 111). The main argument for adopting this (single!) ancient diet is that humans have simply not had enough time to adapt to digesting these kinds of foods, which have only been eaten in their present form since the advent of agriculture. This is simply not true. See the evidence presented at the beginning of the chapter for ground starch grains being baked into a kind of bread 30,000 years ago, the example of the relationship between people who consume high amounts of starch and the number of copies of the amylase gene to help them digest it, or the lactose example of rapid dietary evolution in the previous chapter, evidence presumably ignored by Loren Cordain (author of the bestselling and formative books on the topic, The Paleo Diet) and his devotees. Zuk points out some important facts: people in different places historically eat, and presumably prehistorically ate "different foods; modifying them to different degrees, and thrived on the variety" (p. 125). Additionally, studies of Old World foragers show that gathering, not hunting, provides the majority of their diet - and that even New World foragers get nearly a third of their diet from plants, dispelling myths of modern meat-based diets in these populations across the board. Zuk puts it well here: "The notion that humans got to a point in evolutionary history when their bodies were somehow in sync with the environment, and that sometime later we went astray from those roots - whether because of the advent of agriculture, the invention of the bow and arrow, or the availably of the hamburger - reflects a misunderstanding of evolution. What we are able to eat and thrive on depends on our more than 30 million years of history as primates, not on a single arbitrarily more recent moment in time" (p. 120). She notes that the main problem with modern Western diets seems to be their energy density, which makes it easy to overeat, and that practically all our modern foods - especially plants - are vastly different from what our ancestors ate.

Chapter 6, "Exercising the Paleofantasy", discusses two entertainingly contradictory hypotheses related to exercise and prehistory. The first is that that our ancestors would have engaged in high intensity, brief, intermittent bouts of exercise, so our modern exercise regime should include irregular, strenuous, short sessions of weight training to emulate things like carrying rocks, gathering plants, and butchering animals. The second - the Endurance Running Hypothesis - posits that humans are adapted to walk and run long distances over extended periods of time, and that this adaptation was beneficial for persistence hunting (basically following animals over long distances until they become exhausted). The idea is that this was a key behavioral adaptation in our evolutionary history that led to yet another important dietary change: an increase in the proportion of meat. Either way, it's clear that our sedentary lifestyles are detrimental to our health. Zuk explores the link between this lifestyle and obesity, and the idea that some people are genetically programmed to conserve energy in the face of food scarcity while others increase their activity, possibly to seek food outside their normal foraging ranges - related to the genetic of glucose metabolism and food-triggered diabetes. Zuk presents arguments for and against this hypothesis and comes down tentatively on the side of running being a rare but important prehistoric adaptation. She outlines the corollary idea that barefoot is the "primitive" and therefore "healthier" way to run, and that runners wearing shoes tend to land heel first, leading to more injuries (with forefoot strike more related to the avoidance of injury than wearing 
shoes). The chapter ends with a discussion of recent selection on the gene ACTN3, which produces a protein that controls fast-twitch muscle fibers, and how it may be related to athletic ability.

Chapter 7, "Paleofantasy Love", delves into the provocative notion that human men are genetically programmed to stray, while women's genes make them faithful. After a peacock's tail introduction to sexual selection, Zuk notes that females' reproductive success is limited by the number of children they can produce and raise, while the main reproductive effort of men is in mating itself. Following that logic, females benefit from mating with high quality males because that male's genes will confer a greater ability to survive on her young, making it more likely to pass her genes to future generations - or he'll stick around and help to raise his progeny. In sum: the notion of choosy females (more inclined towards monogamy) and competitive males (driven to polygamy). The chapter then explores the mating proclivities of other great apes and how we might find evidence for our more recent prehistoric mating systems using genetic and linguistic studies of modern humans. She outlines the idea of the unique human sexual division of labor (men the hunters and women the gatherers) and the exchange of meat for fidelity, or "sex contract", but then questions whether hunting is more of a social signal than an essential part of subsistence. Finally, she explores whether body size dimorphism is linked to reproductive behavior in modern humans.

Chapter 8, "The Paleofantasy Family", follows nicely on the previous chapter, exploring how people seek to interpret modern day child rearing practices in terms of our past. Zuk points out the peculiarity of our precocious infants and the generally unique pattern of human growth and development that includes extended periods of childhoods and adolescence. Humans have shorter interbirth intervals than other great apes, and our kids' long period of dependence mean they are more likely to survive to be adults - a piece in the puzzle of our amazing and growing population size. Does that dependence relate to our complex social structure and communication - does it take that long to learn all the tasks one needs to survive and thrive as an adult? Do all the other members of the family who help in child rearing (alloparents), leading to demonstrably beneficial attachment relationships outside of the parents (especially grandmothers), invalidating the idea of a nuclear family as our natural state? Zuk ends this chapter by entering the sensitive realm of evolutionary validation of modern (Western) attachment parenting - babywearing, responding immediately to crying, nursing on demand, and especially cosleeping.

Chapter 9, "Paleofantasy, in Sickness and Health", focuses on how our resistance to disease evolves. Zuk discusses past and present mortality rates and life expectancy, pointing out the difficulty in determining causes of death even in the recent past. She talks about the genetic component of susceptibility to some infectious diseases. She describes how genetic defects cause some diseases and how genes and lifestyle factors mix to affect still other diseases, noting the "deeply rooted nature of disease itself" (p. 227) rather than disease being some newfangled result of recent changes in our daily lives. She also explains how evolution can favor more virulent parasites with an increase in host populations. She spends time describing how understanding our genetic adaptations to resist past diseases, like bubonic plague or smallpox, likely plays a role in current immunity to AIDS - but increased susceptibility to West Nile virus. Again here she points out an important evolutionary misconception: consequences cannot be unintended or unforeseen, because "everything about evolution is unintentional" (p. 233). She ends by discussing how we now know that animal domestication likely did not cause tuberculosis to spread from cattle to humans and how in yet another evolutionary trade-off resistance to tuberculosis causes susceptibility to autoimmune diseases, and that cancer is probably not another "curse of civilization" (p. 239). Perhaps this and other diseases that commonly afflict much older adults are a price we pay for our long life spans.

Chapter 10, "Are We Still Evolving? A Tale of Genes, Altitude, and Earwax", is a reaction to a common view that we are somehow no longer subject to evolutionary forces. There is a common idea that modern technology buffers us from the harsh forces of nature like big predators and the plagues of past - which often conveniently forgets about the toll infectious diseases and epidemics take in the third world, even with modern medicine. Here Zuk reminds us that evolution is not progressing towards a goal (presumed to be people today), that every organism alive today is equally evolved as any other, and that genetic drift is another mechanism of evolution. She explains selective sweeps with the example of earwax and presents in nice detail two examples of very recent human evolution: evidence for changes in body size and physiology from the Framingham Heart Study and adaptation to high altitude. She ends with a lighthearted yet reasoned appeal to abandon the idea that we are simply Stone Age people in a space age world, and that this mismatch of genes and environment is the root of most of our modern ailments.

In this delightful book, you will find witty and engaging writing, useful metaphors and analogies to explain evolution, and consistent corrections of many misconceptions about evolution. You will find examples of recent evolution in humans and other organisms, with a level of detail satisfying for scientists but not overwhelming for novices. I am especially happy to note that Zuk uses footnotes to cite all of her references, which is not often the case in 
books aimed at a general audience. This book could be appropriate to include in readings for a course on evolution, and will for a long time be one of my top 10 popular science books. OK, top 5 !

\section{Competing interests}

The author declares that she has no competing interests.

Received: 21 November 2014 Accepted: 2 December 2014

Published online: 17 December 2014

doi:10.1186/s12052-014-0030-3

Cite this article as: Pobiner: Living the paleofantasy? Evolution: Education and Outreach 2014 7:30.

\section{Submit your manuscript to a SpringerOpen ${ }^{\odot}$ journal and benefit from:}

- Convenient online submission

- Rigorous peer review

- Immediate publication on acceptance

- Open access: articles freely available online

- High visibility within the field

- Retaining the copyright to your article 